\title{
DOS PRIMÓRDIOS À (QUASE) UNIVERSALIZAÇÃO DOS PLANOS DE EDUCAÇÃO NO BRASIL: AVANÇOS E DESAFIOS NO CENÁRIO CONTEMPORÂNEO
}

\author{
Silvio Cesar Nunes Militão ${ }^{1}$ \\ Maria Alice de Miranda Aranda ${ }^{2}$
}

Resumo: Este artigo objetiva analisar avanços e desafios atinentes à formulação e materialização dos planos de educação, a partir de uma perspectiva histórica e contemporânea. Metodologicamente, vale-se de pesquisa bibliográfica e documental. Os resultados evidenciam que inexiste no Brasil uma tradição em pautar a educação mediante planos de Estado sistêmicos e de longo prazo, com a (quase) universalização dos planos subnacionais sendo ineditamente atingida somente na corrente década. Porém, os resultados indicam que a efetiva materialização destes planos demandará, além de sistemáticas de monitoramento e avaliação, uma radical alteração na rota política e econômica em curso, a qual inviabiliza a consecução das metas dos múltiplos planos vigentes.

Palavras-chave: Planejamento Educacional,Plano Nacional de Educação,PlanosSubnacionaisde Educação,PolíticaEducacional.

\section{From the earliest (almost) universalization of education plans in Brazil: advances and challenges in contemporary scenario}

\begin{abstract}
This article aims to analyze advances and challenges related to the formulation and materialization of education plans, from a historical and contemporary perspective. Methodologically, it uses bibliographic and documentary research. The results show that in Brazil there is no tradition of guiding education through systemic and long-term state plans, with the (almost) universalization of subnational plans being unheard of only in the current decade. However, the results indicate that the effective materialization of these plans will require, in addition to systematic monitoring and evaluation, a radical change in the current political and economic route, which makes it impossible to achieve the goals of the multiple plans in force.

Keywords:Educational Planning,National Education Plan,Subnational Education Plans,Educational policy.
\end{abstract}

\footnotetext{
'Universidade Estadual Paulista Júlio de Mesquita Filho. (scnmilitao@gmail.com)

${ }^{2}$ Universidade Federal da Grande Dourados. (marialicearanda@gmail.com)
} 


\section{INTRODUÇÃO}

Este artigo é parte constituinte de pesquisa mais ampla intitulada "Monitoramento do Planos Decenais de Educação na Região Administrativa de Marília (SP)", voltada ao mapeamento e análise dos mecanismos de implementação, monitoramento e avaliação dos Planos Municipais de Educação (PMEs) jurisdicionados à Região supracitada, desenvolvida em nível de pós-doutoramento junto ao Programa de Pós-Graduação em Educação da Universidade Federal da Grande Dourados (PPGEdu/UFGD), financiada pelo Programa Nacional de Pós-Doutorado (PNPD/CAPES).

O objetivo precípuo deste artigo, particularmente, consiste em analisar os principais avanços e desafios atinentes à formulação e materialização dos planos decenais de educação, a partir de uma perspectiva histórica e contemporânea.

Para tanto, ancorado numa abordagem qualitativa, o trabalho vale-se de pesquisa bibliográfica e documental acerca da temática em abordagem, bem como de coleta e análise de dados relativos aos planos subnacionais de educação disponibilizados na plataforma "PNE em Movimento" do Ministério da Educação (MEC).

Para fins de apresentação, este texto encontra-se organizado em quatro partes constituintes, incluídas desta introdução. Assim, na seção seguinte, apresenta-se um panorama histórico acerca dos principais intentos de formulação de planos de educação no Brasil e as marchas e contramarchas concernentes à concretização ou secundarização dos mesmos, das primícias ao advento do Plano Nacional de Educação (PNE) em vigência. Na seção subsequente, além de demonstrar o processo de (quase) universalização dos planos de educação infranacionais alinhados ao PNE 2014-2024, aborda-se os avanços e desafios referentes à efetiva materialização de tais planos educacionais face a um contexto político, social e econômico contemporâneo marcadamente adverso. Por fim, apresentam-se as considerações finais. 


\section{PLANOS DE EDUCAÇÃO NO BRASIL: DO MANIFESTO DOS PIONEIROS DA EDUCAÇÃO NOVA AO PNE 2014-2024}

A ideia de um planejamento educacional de "[...] Estado, para além dos governos, com dimensão nacional, de responsabilidade de todos os entes federados e abrangendo os diferentes níveis e etapas da educação" (BORDIGNON, 2009, p. 91), remonta à década de 1930, cujo marco histórico é o "Manifesto dos Pioneiros da Educação Nova" lançado em 1932. Desde então, vários foram os intentos no sentido de pautar a educação brasileira mediante planos educacionais, não obstante os fortes obstáculos encontrados à sua efetiva materialização pois, como bem ressalta Dourado (2017b, p.12):

[...] a relação entre proposição e aprovação do plano não é linear ao seu processo de materialização como política pública. Ou seja, a materialização do PNE implica ações e políticas que se efetivam, a partir de vários embates e conjunturas, que contribuem para a efetivação do plano ou para a sua secundarização.

A Constituição Federal (CF) de 1934 (BRASIL, 1934), sob forte influência do referido Manifesto, estabeleceu como competência da União "fixar o plano nacional de educação" (art. 150) e incumbiu o Conselho Nacional de Educação (CNE) da sua elaboração (art. 152). Elaborado pelo órgão colegiado mencionado, o projeto de Plano Nacional de Educação (PNE) foi encaminhado à apreciação da Câmara dos Deputados em maio de 1937 mas, em razão do advento do Estado Novo, a sua tramitação foi interrompida e o PNE "acabou sendo deixado de lado" (SAVIANI, 2008, p. 179).

Após a derrocada do Estado Novo, sob a vigência da CF de 1946 (BRASIL, 1946) e da nossa primeira Lei de Diretrizes e Bases da Educação Nacional - Lei no 4.024/61 (BRASIL, 1961), uma outra proposta de PNE foi formulada pelo Conselho Federal de Educação $(\mathrm{CFE})^{3} \mathrm{em} \mathrm{1962.} \mathrm{Contudo,} \mathrm{sem}$ ser aprovado como lei (LOUREIRO, 2016) e num quadro de acentuada inflexão política e social com “[...] a renúncia de Jânio Quadros e as

${ }^{3}$ Com a edição e vigência da Lei no 4.024/61, o CNE foi transformando em CFE. Entretanto, com o advento da Lei $n^{\circ} 9.131$ de 1995, o CNE ressurgiu no lugar do extinto CFE. 
turbulências subsequentes [...]" (SCAFF; OLIVEIRA; LIMA, 2018, p. 908), tal documento não foi efetivamente implementado.

Ao resgatarem a trajetória dos planos nacionais de educação elaborados no percurso histórico brasileiro, Scaff, Oliveira e Lima (2018, p. 906) constataram "[...] sua fragilidade frente as oscilações políticas e sociais em seu entorno, o que tem comprometido severamente a efetivação e, inclusive, a aprovação de todos os planos elaborados [...]”. Segundo as autoras supracitadas (2018, p. 918), via de regra, as tentativas de elaboração dos referidos planos no Brasil "[...] foram obstruídas por golpes de Estado, que interromperam a democracia em âmbito nacional, instaurando períodos ditatoriais caracterizados pela centralização do planejamento [...]”.

Tal fato foi registrado em 1937, cuja ditadura instaurada pelo denominado "Estado Novo" interrompeu o processo democrático de construção do PNE, então, mobilizado pelo Movimento dos Educadores da Educação Nova. Embora o ideário de planejamento educacional tenha sido retomado com a abertura democrática do país, em 1945, outro golpe de estado interrompe o já avançado processo de elaboração do PNE de 1962, dando início ao longo período ditatorial, que se estendeu de 1964 a 1985, concentrando o planejamento nas mãos da tecnocracia [...] (SCAFF; OLIVEIRA; LIMA, 2018, p. 919).

Resultante de amplo processo constituinte e com notórios avanços no campo dos direitos sociais, a CF de 1988 veio retomar a ideia de planejamento pensado exclusivamente para a área educacional, conforme disposto no seu artigo 214: "A lei estabelecerá o plano nacional de educação, de duração plurianual ${ }^{4}$, visando à articulação e ao desenvolvimento do ensino em seus diversos níveis e à integração das ações do poder público" (BRASIL, 1988). Ao determinar a instituição de um PNE estabelecido por lei, a CF de 1988 visou assegurar "a continuidade das políticas educacionais independentemente do governo, caracterizando-o mais como plano de Estado do que como plano governamental, o que é uma das vantagens de sua aprovação como lei” (LIBÂNEO; OLIVEIRA; TOSCHI, 2003, p. 159).

Apesar dessa determinação legal, somente após quase 10 anos da aprovação da CF/1988, e a partir de mobilização da sociedade civil organizada pelo Fórum Nacional em Defesa da Escola Pública (FNDEP), foi elaborada

\footnotetext{
${ }^{4}$ Redefinido posteriormente como "decenal” pela Emenda Constitucional no ${ }^{\circ}$ 59/2009.
} 
uma proposta de PNE, após a realização de dois Congressos Nacionais de Educação, em 1996 e 1997, respectivamente (PERONI; FLORES, 2014).

A proposta elaborada pelo FNDEP foi apresentada pelo Deputado Ivan Valente com o Projeto de Lei no ${ }^{4}$ 4.155/1998. Em confronto com essa proposta, em 11 de fevereiro de 1998 o Poder Executivo enviou ao Congresso Nacional a Mensagem Presidencial 180/1998 que resultou na tramitação do Projeto de Lei $\mathrm{n}^{\mathrm{o}}$ 4.173, em 13 de março do mesmo ano.

Após anos de embate entre os dois projetos, foi aprovada a Lei $\mathrm{n}^{\circ}$ 10.172/2001 que estabeleceu o PNE para o decênio 2001-2010. Segundo Dourado (2011, p. 25), a aprovação do Plano foi resultado da "[...] hegemonia governamental no Congresso Nacional, que buscou traduzir a lógica de suas políticas em curso".

Acerca do processo de elaboração e aprovação do primeiro PNE brasileiro instituído por lei específica, Scaff e Oliveira (2018, p. 143) afirmam que

\begin{abstract}
O primeiro PNE elaborado sob a égide da Constituição Federal de 1988 foi marcado pela ampla participação da sociedade brasileira, por meio de dois Congressos Nacionais de Educação (CONED) e amplos debates realizados por todo o país, sob a coordenação do Fórum Nacional em Defesa da Escola Pública (FNDEP). No entanto o projeto elaborado pela sociedade brasileira não logrou êxito, uma vez que contestava o projeto neoliberal do governo federal em curso. Após longo percurso de debates e enfrentamentos, o documento aprovado e sancionado pela Lei n.10.172, de 9 de janeiro de 2001 (BRASIL, 2001), restou comprometido diante dos limites orçamentários que impediam a concretização de suas metas.
\end{abstract}

Ao avaliar o PNE 2001-2010 já expirado, Dourado (2010, p. 685) aponta os limites à sua concretização, advindos das "[...] restrições à gestão e ao financiamento da educação, em função de nove vetos presidenciais ao que fora delineado", configurando-se como "plano formal, marcado pela ausência de mecanismos concretos de financiamento", não se efetivando, assim, comodiretriz central para as políticas, o planejamento e a gestão da educação nacional. "Exemplo desse fato encontra-se no reduzido número de planos estaduais e municipais de educação aprovados em decorrência de tal PNE, embora se constituísse em exigência legal” (SCAFF; OLIVEIRA; LIMA, 2018, p. 911). 
Não obstante a Lei n⿳⺈ 10.172/2001 determinar, em seu artigo $2^{\circ}$, que a partir da sua vigência, os Estados, o Distrito Federal e os Municípios deveriam, com base no PNE aprovado, elaborar planos decenais correspondentes, ao findar a vigência do PNE 2001-2010, apenas 12 (46\%) dos estados brasileiros possuíam seus Planos Estaduais de Educação (PEEs) aprovados por lei e somente $3.384(60,8 \%)$ dos municípios do país haviam aprovado seus Planos Municipais de Educação (PMEs) (BRASIL, 2014b; SOUZA; ALCÂNTARA, 2016).

Carente de organicidade interna, exagerado quanto ao número de metas fixadas - 297 ao todo, denotando "[...] um alto índice de dispersão e perda do senso de distinção entre o que é principal e o que é acessório" (SAVIANI, 2008, p. 275) - e sem prever mecanismos concretos e eficazes para o correspondente monitoramento e avaliação da sua implementação, o PNE 2001-2010 na prática não se traduziu como mecanismo de regulação capaz de “[...] nortear as diretrizes de planejamento, gestão e efetivação das políticas educacionais, como se espera de um plano nacional que contribua para o pacto federativo" (DOURADO, 2010, p. 688).

Mais recentemente, após disputado, completo e moroso processo de tramitação no Congresso Nacional, foi aprovado pela Lei n⿳ำ 13.005/2014 o PNE para o decênio 2014-2024, composto por 14 Artigos, 20 Metas e 254 Estratégias voltadas a todos os níveis, etapas e modalidades de ensino, de modo a representar um novo alento em termos de planejamento educacional como política de Estado.

$\mathrm{O}$ processo de elaboração/aprovação do $\mathrm{PNE}$ em vigência avançou em relação ao PNE findado ao ser fruto, também, de ampla participação da sociedade civil, como bem sintetizado por Martins, Pimenta e Novaes (2014, p. 282):

No dia 25 de junho de 2014, a presidente Dilma Rousseff sancionou (sem vetos) o Plano Nacional de Educação, [...] após quase quatro anos de tramitação durante os quais negociações foram encetadas entre legisladores, representantes do governo, entidades do magistério e da sociedade civil organizada. Nesse processo, o Projeto de Lei 0.035/2010 (PNE), encaminhado pelo executivo federal, recebeu milhares de propostas de emendas, tendo sido a maior parte delas discutida e deliberada na Conferência Nacional de Educação (Conae) em 2010, durante a qual participaram quase dois mil municípios e três mil delegados. 
Com uma estrutura mais enxuta e objetiva do que a do PNE precedente, o PNE vigente, "[...] se entendido como eixo das políticas educacionais, pode representar um avanço para a educação básica e superior, a despeito de alguns limites, tensões e ambiguidades do texto aprovado" (DOURADO, 2017a, p. 26).

A Lei nº 13.005/2014, em seu artigo $8^{\circ}$, estabeleceu, também, que todos os entes federativos subnacionais deveriam "elaborar seus correspondentes planos de educação, ou adequar os planos já aprovados em lei, em consonância com as diretrizes, metas e estratégias previstas [no atual] PNE, no prazo de 1 (um) ano contado da publicação desta Lei (BRASIL, 2014a).

A referida exigência, segundo Scaff, Oliveira e Aranda (2018, p. 135), “[...] culminou em intensos movimentos nos estados e municípios em direção à organização da comunidade para o cumprimento de tal dispositivo legal”. A próxima seção, portanto, trata dos avanços e desafios atinentes à efetiva materialização dos planos de educação elaborados/adequados na vigência do PNE 2014-2024.

\section{A (QUASE) UNIVERSALIZAÇÃO DOS PLANOS DE EDUCAÇÃO NO CENÁRIO CONTEMPORÂNEO: AVANÇOS E DESAFIOS}

A aprovação do PNE 2014-2024 desencadeou no Brasil um processo generalizado e célere de elaboração (ou adequação) de planos subnacionais de educação, o qual envolveu praticamente todos os entes federativos, conforme se visualiza no quadro 1.

Quadro 1 - Situação dos Planos subnacionais de Educação no Brasil-2019

\begin{tabular}{|l|r|r|}
\hline \multicolumn{1}{|c|}{ Esferas de Poder/Situação dos Planos } & Quantidade & \multicolumn{1}{|c|}{$\%$} \\
\hline Estados/Distrito Federal com Lei sancionada & 26 & 96,3 \\
\hline Estado com Documento-Base elaborado & 1 & 3,7 \\
\hline Municípios com Lei sancionada & 5.568 & 99,96 \\
\hline Municípios com projeto de Lei enviado ao Legislativo & 2 & 0,04 \\
\hline
\end{tabular}

Fonte: elaboração própria, a partir de dados coletados na página do MEC denominada " PNE em Movimento - Situação dos Planos de Educação”, visitada em 10/07/2019. 
A análise dos dados do quadro 1 mostra que a quase totalidade dos estados e municípios brasileiros, além do Distrito Federal, cumpriram o disposto no artigo $8^{\circ}$ da Lei $n^{\circ}$ 13.005/2014 e elaboraram/adequaram seus respectivos planos decenais de educação em conformidade com as diretrizes, metas e estratégias dispostas no PNE em vigência.

Das 27 unidades da Federação, 26 (ou 96,3\%) possuem PEEs sancionados por lei e apenas um (ou 3,7\%) único estado (Rio de Janeiro) ainda não converteu seu correspondente plano em norma jurídica. Dos 5.570 municípios brasileiros, enquanto 5.568 (ou 99,96\%) deles já aprovaram seus respectivos PMEs na forma da Lei, somente 2 (ou 0,04\%) ainda não o fizeram (Iaras e Ribeirão Preto, ambos do estado de São Paulo).

A elevada taxa de aprovação legal dos referidos planos subnacionais representa um grande avanço em termos de planejamento educacional sistêmico e de Estado no Brasil, atingindo, ineditamente, a (quase) universalização.

Com tal "[...] universalização, impera-se o desafio de fazer com que esses planos sejam o norte das políticas educacionais, que pautem os programas de governos para os próximos dez anos (ALVES, 2017, p. 2316).

Cumpre destacar que dois fatores, dentre outros, contribuíram sobremaneira para o alcance da (quase) universalização dos planos educacionais infranacionais alinhados ao vigente planejamento da educação nacional, a saber:

O primeiro refere-se ao movimento associado ao estabelecimento de uma maior delineamento legal, vinculado aos Planos subnacionais decorrentes, do primeiro para o segundo PNE. Embora o PNE 2001-2010 determinasse que, a partir da sua vigência, os entes subnacionais deveriam, "com base no Plano nacional de Educação, elaborar planos decenais correspondentes" (Lei $\mathrm{n}^{\circ} 10.172,2001$, Art. $2^{\circ}$ ), ao não fixar prazos para o cumprimento dessa determinação legal, além de possibilitar que tais Planos fossem aprovados tanto ao longo de todo o período de vigência do PNE 2001-2010 como também fora desse período, oportunizou também que alguns Planos sequer fossem elaborados. Buscando contornar esse problema, o PNE 2014-2024, conforme já evidenciado, fixou o prazo de um ano, a partir da sua publicação, para a elaboração ou adequação dos Planos subnacionais, prazo esse expirado no dia 25 de junho de 2015 [...].Um segundo fator [...] diz respeito ao movimento que envolveu diversas ações articuladas entre a União e os 
demais entes federados. Mais especificamente, a partir da Secretaria de Articulação com os Sistemas de Ensino (SASE/MEC), o Governo Federal oportunizou assessoramento aos entes subnacionais, concretizado por meio da constituição de uma rede de assistência técnica integrada por avaliadores educacionais, aos quais foi disponibilizado um certo conjunto de documentos, com vistas a apoiar a construção dos referidos Planos [...] (MENEZES; SOUZA, 2018, p. 622).

A despeito do exitoso processo de elaboração/adequação dos planos decenais de educação levado a cabo pelas distintas esferas públicas de poder, Pinto $(2017$, p. 17) sabiamente adverte que, "[...] como a experiência brasileira mostra, se não é fácil aprovar um plano de educação, mais difícil ainda é garantir sua implantação de forma efetiva”.

Assim, uma vez elaborados e aprovados os planos decenais de educação pelos entes federativos brasileiros, "[...] desafio maior ainda será o processo de implementação, monitoramento e avaliação destes planos [...]” (NASCIMENTO; GROSSI JÚNIOR; PEREIRA, 2017, p. 125).

Partindo do pressuposto defendido por Dourado (2017a) de que não há uma relação simples e linear entre os processos de proposição e materialização das políticas educacionais, o monitoramento e a avaliação "[...] figuram-se como ações imprescindíveis para o êxito dos Planos de Educação, garantindo subsídios aos gestores e à sociedade civil sob o cumprimento ou não das metas e estratégias propostas e possibilitando a readequação destas caso necessário" (ALVES, 2017, p. 2316-2317).

Cruciais "na fase de implementação do plano, de jogar o jogo, de colocar em marcha as estratégias da caminhada rumo às metas [...]" (BORDIGNON, 2014, p. 36), o monitoramento e avaliação são etapas distintas e complementares de um processo único (DOURADO; GROSSI JÚNIOR; FURTADO, 2016) e assim podem ser definidos:

[...] o monitoramento é um processo contínuo, que precisa produzir informações com grande celeridade, pois deve subsidiar as decisões sobre a condução das políticas, programas e projetos. A avaliação é um exame realizado em profundidade, que produz informações complexas e poderá ou não ser usada na tomada de decisões (MALCONES, 2012, p. 15). 
A complexidade da implementação de planos educacionais de longo prazo demanda, portanto, um processo em que:

\begin{abstract}
O monitoramento se torne um ato contínuo de observação pelo qual são tornadas públicas as informações a respeito do progresso que vai sendo feito para o alcance das metas definidas. A avaliação seja entendida como o ato periódico de dar valor aos resultados alcançados até aquele momento, às ações que estejam em andamento e àquelas que não tenham sido realizadas, para determinar até que ponto os objetivos estão sendo atingidos e para orientar a tomada de decisões (BRASIL, 2016, p. 6)
\end{abstract}

Considerando que "a ausência de monitoramento e avaliação [...] afeta bastante a realização da própria política e, consequentemente, seus resultados” (PARENTE; PEREZ; MATTOS, 2011, p. 26), a Lei 13.005/2014 avançou ao estipular monitoramento contínuo e avaliações periódicas acerca da execução e cumprimento das metas e estratégias do PNE 2014-2024 e de seus congêneres

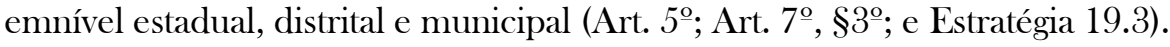

A referida Lei Federal, em seu artigo $5^{\circ}$, define as instâncias responsáveis pela realização do monitoramento contínuo e das avaliações periódicas das metas e estratégias do PNE, quais sejam:

I - Ministério da Educação - MEC;

II - Comissão de Educação da Câmara dos Deputados e Comissão de Educação, Cultura e Esporte do Senado Federal;

III - Conselho Nacional de Educação - CNE;

IV - Fórum Nacional de Educação (BRASIL, 2014a).

Na precisa explicação de Dourado, Grossi Júnior e Furtado (2016, p. 457):

Como decorrência do PNE, os planos de educação dos Estados, do Distrito Federal e dos Municípios também devem ser monitorados e avaliados periodicamente, com a verificação do cumprimento dos dispositivos legais e da implementação das políticas educacionais no âmbito de cada território, contribuindo, assim, para a efetividade do PNE, que só logrará êxito se todos os planos subnacionais cumprirem com os objetivos propostos. 
Assim, de forma análoga a lei do PNE, os planos infranacionais de educação, além de prever sistemáticas de monitoramento e avaliação dos referidos documentos, devem também definir expressamente quais serão os atores institucionais encarregados desta imperiosa tarefa. Nesse sentido, Oliveira et al (2016, p. 31) elencam as instâncias mais indicadas para tal incumbência:

a) Nos estados:

- Secretaria Estadual de Educação;

- Comissão de Educação da Assembleia;

- Conselho Estadual de Educação (CEE);

- Fórum Estadual de Educação.

b) Nos municípios:

- Secretaria Municipal de Educação;

- Comissão de Educação da Câmara ou a própria Câmara;

- Conselho Municipal de Educação;

- Fórum Municipal de Educação.

No intuito de viabilizar a consecução das metas e estratégias dos planos de educação das distintas esferas subnacionais de poder, a Rede de Assistência Técnica vinculada a SASE, após assessorar o correspondente processo de elaboração dos referidos documentos decenais, deu continuidade a partir de 2015 ao trabalho de apoio aos entes federativos mediante construção e disponibilização - via adesão - de metodologia voltada à sistematização e realização de processos de monitoramento e avaliação desses planos.

Quadro 2 - Panorama de adesão dos entes subnacionais à Rede de Assistência Técnica para monitoramento e avaliação dos Planos Decenais de Educação - 2019

\begin{tabular}{|l|r|r|}
\hline \multicolumn{1}{|c|}{ Esferas de Poder/Situação da adesão } & Quantidade & \% \\
\hline Estados/Distrito Federal com adesão à Rede de Assist. Técnica & 25 & 92,6 \\
\hline Estados sem adesão à Rede de Assist. Técnica & 2 & 7,4 \\
\hline Municípios com adesão à Rede de Assist. Técnica & 5.517 & 99,05 \\
\hline Municípios sem adesão à Rede de Assist. Técnica & 53 & 0,95 \\
\hline
\end{tabular}

Fonte: elaboração própria, a partir de dados coletados na página do MEC denominada " PNE em Movimento - Monitoramento e Avaliação dos Planos Subnacionais de Educação”, visitada em $10 / 07 / 2019$.

A análise dos dados do quadro 2 revelaque a grande maioria dos entes federativos veio compreender a crucial importância da realização de processos de monitoramento e avaliação para o êxito dos planos educacionais em curso, 
sendo vultoso o número de adesões à Rede de Assistência Técnica da SASE para tal empreitada.

Assim, atualmente registra-se adesão à referida rede em 25 (ou 92,6\%) das 27 unidades da Federação, 25 (ou 92,6\%) e em 5.517 (ou 99,05\%) dos 5.570 municípios brasileiros. Em contrapartida, em apenas dois (ou 7,4\%) estados (Minas Gerais e Rio de Janeiro) e em 53 (ou 0,95\%) municípios (sendo: 1 da Bahia, 1 do Espírito Santo, 25 de Minas Gerais e 26 de São Paulo) não se verifica tal adesão.

Não obstante a expressiva adesão observada, a efetiva materialização do PNE 2014-2024 e dos correspondentes planos educacionais subnacionais como epicentro de políticas para o setor configura-se como um enorme desafio diante do cenário político, social e econômico vigente, "[...] cujo compasso e descompasso retratam a quadra complexa em que se encontra o Estado brasileiro, atropelado pelo impeachment da Presidenta eleita e pela adoção de políticas de ajuste fiscal que caminham na contramão das políticas sociais [...]" (DOURADO, 2017a, p. 23).

No cenário nacional contemporâneo, caracterizado por fortes retrocessos políticos, sociais, ajuste fiscal e constantes ataques à democracia que inicia-se no governo federal ilegítimo e antipopular de Michel Temer "[...] instalado em consequência de um golpe jurídico-midiático-parlamentar [...]" (SAVIANI, 2018, p. 45) de meados de 2016, e que tem continuidade no novovelho governo liberal-conservador de Jair Bolsonaro debutado em 2019 - a efetiva materialização das metas do PNE 2014-2024 e dos planos infranacionais mostra-se substancialmente comprometida.

Ao instituir novo regime fiscal e "congelar" por vinte anos os gastos públicos, a Emenda Constitucional no 95, de 15 de dezembro de 2016, concorre sobremaneira para a "morte" do PNE vigente e também do plano subsequente, como bem observa Amaral (2016, p. 654): "esses 20 anos, que se estenderão até 2036, abrangerão o período do PNE [2014-2024] e também o período do próximo PNE que deverá ser o de 2025 a 2035”.

Ao inviabilizar a consecução da meta 20 concernente à ampliação do investimento público em educação ao patamar de $10 \%$ do Produto Interno Bruto (PIB) até o final de 2024, o corrente ajuste fiscal fragiliza consideravelmente todo o PNE e o conjunto dos demais planos decenais a ele articulados, uma vez que a meta financeira de qualquer plano educacional 
consiste na "meta das metas", ou seja, "[...] se constitui como a condição prévia e necessária de viabilidade de todas as demais metas" (SAVIANI, 2008, p. 317).

Acirrando a agenda neoliberal retomada pelo governo Temer pósimpeachment, o atual governo de Jair Bolsonaro, além de manter a política econômica centrada no ajuste fiscal e de avançar na supressão dos direitos sociais (cuja aprovação ${ }^{5}$ da malfadada Reforma da Previdência constitui exemplo emblemático), aventa apresentar, também, uma Proposta de Emenda Constitucional (PEC) visando a desvinculação total das receitas da União.

Se tal PEC vingar, além de representar mais um duro golpe na concretização do PNE 2014-2024 e dos demais planos decenais de educação de estados e municípios uma vez que implicará em consideráveis alterações nos orçamentos educacionais das distintas esferas públicas de poder, poderá inviabilizar, ainda, a criação do chamado FUNDEB Permanente ${ }^{6}$, pois o referido Fundo consiste em uma subvinculação dos recursos constitucionalmente vinculados à educação.

Ademais, ao extinguir a $\mathrm{SASE}^{7}$ - órgão responsável pela articulação entre os planos decenais de educação e pela promoção de assistência técnica relativa ao processo de monitoramento e avaliação dos mesmos - o governo Bolsonaro sinaliza claramente a não assunção do PNE 2014-2024 como política de Estado e principal documento norteador das políticas educacionais do País e, ao secundariza-lo, busca isentar-se principalmente do cumprimento da meta 20, considerada pela equipe econômica capitaneada por Paulo Guedes e pelo (anti)Ministro da Educação como desmedida.

\footnotetext{
${ }^{5}$ A Reforma da Previdência foi aprovada em $1^{\circ}$ turno pela Câmara dos Deputados no dia 12 de julho de 2019, por 379 votos favoráveis e 131 contrários, devendo passar ainda por 2oㅡ turno de votação na Casa antes de seguir para tramitação no Senado Federal.

${ }^{6}$ Diante das limitações orçamentárias do Fundo de Manutenção e Desenvolvimento da Educação Básica e de Valorização dos Profissionais da Educação (FUNDEB), bem como da iminência da sua extinção (2020), existe no Congresso Nacional propostas para tornar o FUNDEB Permanente (o qual seria incluído no texto permanente da Constituição Federal mediante a inserção do art. 212-A) e elevar a alíquota de complementação de recursos da União ao Fundo: PEC 15/2015 da deputada Raquel Muniz (PSC-MG); PEC 33/2019 do senador Jorge Kajuru (PSB-GO); e PEC 65/2019 do senador Randolfe Rodrigues (REDE-AP).

${ }^{7}$ A SASE foi extinta por meio do Decreto n 9.465, de 02/01/2019. Além dela, também foi extinta a Secretaria de Educação Continuada, Alfabetização, Diversidade e Inclusão (SECADI) e, para seu lugar, foram criadas a Secretaria de Alfabetização (SEALF) e Secretaria de Modalidades Especializadas de Educação (SEMESP).
} 


\section{CONSIDERAÇÕES FINAIS}

Ao procedermos com a análise da trajetória histórica do planejamento educacional e dos planos de educação no Brasil, constatamos que inexiste no País larga tradição em pautar o setor mediante planos de Estado, sistêmicos e de longo prazo.

Prova desta afirmação é que a (quase) universalização da aprovação/vigência legal do conjunto dos planos educacionais decenais dos múltiplos entes federativos é ineditamente atingida somente em meados da corrente década, configurando - ainda que tardiamente - notável avanço em termos de planejamento educacional articulado e balizador das políticas de educação deflagradas pelas três esferas administrativas de governo.

Entretanto, no bojo de um cenário político e econômico continuamente adverso, o horizonte de concretização do PNE 2014-2024 e dos demais planos decenais congêneres parece distanciar-se cada vez mais.

Depreende-se, portanto, que a efetiva materialização de tais planos demandará, além de ações concretas e sistemáticas de monitoramento e avaliação, uma radical alteração na rota política e econômica atualmente trilhada pelo País, a qual, centrada na supressão de direitos sociais e no ajuste fiscal, concorre sobremaneira para inviabilizar a consecução das metas e estratégias dos planos decenais de educação vigentes.

Indubitavelmente, a superação do cenário político e econômico em curso e o correspondente restabelecimento do PNE 2014-2024 como política de Estado para a educação nacional passará, necessariamente, por ampla mobilização e contínua resistência ativa da sociedade civil, tal qual advoga Saviani (2016, p. 392):

Nessa fase difícil que estamos atravessando, resulta imprescindível combatermos as medidas restritivas dos direitos sociais, entre eles, o direito a uma educação de qualidade acessível a toda a população. Essa foi e continua sendo, agora de forma ainda mais incisiva, a nossa luta. A luta de todos os educadores do Brasil (SAVIANI, 2016, p. 392). 


\section{REFERÊNCIAS}

ALVES, Edson Ferreira.Universalização da aprovação de planos de educação por estados e municípios: o que vem depois? In: XXVIII Simpósio de Política e Administração da Educação, 2017, João Pessoa, PB. Anais...UFG: ANPAE, 2017. v. 45. p. 2307-2318.

BORDIGNON, G. Gestão da educação no município: sistema, conselho e plano. São Paulo: Editora e Livraria Instituto Paulo Freire, 2009.

BORDIGNON, Genuíno. Caminhar da educação brasileira: muitos planos, pouco planejamento. In: SOUZA, Donaldo Bello de; MARTINS, Angela Maria (Orgs.). Planos de Educação no Brasil: planejamento, políticas, práticas. São Paulo: Edições Loyola, 2014. p. 29-53.

BRASIL. Constituição da República Federativa do Brasil, 1988. Brasília: Senado Federal, Centro Gráfico, 1988.

. Constituição da República dos Estados Unidos. Rio de Janeiro,1934.

. Constituição dos Estados Unidos do Brasil. Rio de Janeiro,1946.

BRASIL.Lei $n^{\circ}$ 13.005, de 25 de junho de 2014. Aprova o Plano Nacional de Educação e dá outras providências. Diário Oficial da União, Brasília, DF, 26. jun. 2014. Seção 1, p.01. 2014a.

. Emenda Constitucional no 95, de 15 de dezembro de 2016. Altera o ato das disposições constitucionais transitórias, para instituir o novo regime fiscal, e dá outras providências. Brasília: 2016.

. Emenda Constitucional no 59, de 11 de novembro de 2009. Diário Oficial da União, Brasília, DF, 12. nov. 2009.

. Lei n ${ }^{\circ}$ 10.172, de 09 de janeiro de 2001. Aprova o Plano Nacional de Educação e dá outras providências. Brasília, 2001.

Lei no 9.394, de 20 de dezembro de 1996. Dispõe sobre as Diretrizes e Bases da Educação Nacional. Brasília: 1996.

. Lei $n^{\circ}$ 4.024, de 20 de dezembro de 1961. Fixa as Diretrizes e Bases da Educação Nacional. Brasília: 1961. 
- Ministério da Educação. Secretaria de Articulação com os Sistemas de Ensino (SASE). O Plano Municipal de Educação: Caderno de Orientações. Brasília: MEC, 2014.

- Ministério da Educação. Secretaria de Articulação com os Sistemas de Ensino (SASE). Caderno de Orientações para Monitoramento e Avaliação dos Planos Municipais de Educação. Brasília: MEC, 2016b.

DOURADO, Luiz Fernandes. Avaliação do Plano Nacional de Educação 20012009: questões estruturais e conjunturais de uma política. Educação e Sociedade,Campinas, v.31, n.112, p.675-705. jul-set. 2010. Disponível em: < http://www.scielo.br/pdf/es/v31n112/03>. Acesso em: 29 out. 2017.

. Plano Nacional de Educação como política de Estado: antecedentes históricos, avaliação e perspectivas. In: DOURADO, Luiz Fernandes Dourado (Org.). Plano Nacional de Educação (2011-2020): avaliação e perspectivas. 2 Ed. Goiânia: Editora UFG; Belo Horizonte: Autêntica Editora, 2011. p. 17-59.

Plano Nacional de Educação:o epicentro das políticas de estado para a educação brasileira. Goiânia: Editora da Imprensa Universitária/ANPAE, 2017 a.

, Luiz Fernandes (Org.). Plano Nacional de Educação - PNE

2014/2024: avaliação e perspectivas. Campinas, SP: Mercado de Letras, 2017b.

DOURADO, Luiz Fernandes; GROSSI JUNIOR, Geraldo; FURTADO, Roberval Ângelo. Monitoramento e avaliação dos planos de educação: breves contribuições.RBPAE - v. 32, n. 2, p. 449 - 461 mai./ago. 2016.

LIBANEO, José Carlos; OLIVEIRA, João Ferreira; TOSCHI, Mirza Seabra. Educação escolar: políticas, estrutura e organização. São Paulo: Cortez, 2003.

LOUREIRO, Walderês Nunes. Os planos de educação: estadual e municipal. OLIVEIRA, João Ferreira; AGUIAR, Márcia Angela da S. (Orgs.). Planos de Educação e Ações Articuladas. Camaragibe, PE: CCS Gráfica e Editora, 2016. p. 17-36.

MALCOMES, Irma Carina Brum. Monitoramento e avaliação de políticas públicas de saúde no município de Eldorado do Sul. 2012. Monografia. (Especialização em Gestão Pública Municipal) - Universidade Federal do Rio Grande do Sul. 
MARTINS, Angela Maria; PIMENTA, Cláudia Oliveira; NOVAES, Gláucia Torres Franco. Planos municipais de educação: potencialidades e limites de municípios na elaboração de instrumentos de planejamento. In: SOUZA, Donaldo Bello de; MARTINS, Angela Maria (Orgs.). Planos de Educação no Brasil: planejamento, políticas, práticas. São Paulo: Edições Loyola, 2014. p. 277-302.

MENEZES, Janaína Specht da Silva; SOUZA, Donaldo Bello de. Monitoramento e avaliação nos Planos Estaduais de Educação consoantes ao novo PNE. Pró-Posições, v. 29, p. 614-639, 2018.

NASCIMENTO, Gilvânia da Conceição; GROSSI JUNIOR, Geraldo; PEREIRA, Jhonata Moreira. Planos Municipais de Educação: perfil dos municípios que não possuíam plano municipal de educação no segundo ano de vigência da Lei n. 13.005/14. Revista Exitus, Santarém/PA, Vol. 7, n. 1, p. 108130, jan./abr. 2017.

OLIVEIRA, João Ferreira et al. Planos Estaduais, Distrital e Municipais de Educação: monitoramento e avaliação - Caderno Temático ANPAE 4. Camaragibe, PE: CCS Gráfica e Editora, 2016.

PARENTE, Cláudia da Mota Darós; PEREZ, José Roberto Rus; MATTOS, Maria José Viana Marinho de. Avaliação, monitoramento e controle social: contribuição à pesquisa e à política educacional. In: PARENTE, Cláudia da Mota Darós; PARENTE, Juliano Mota (Orgs.). Avaliação, política e gestão da educação. São Cristóvão: Editora UFS, 2011. p. 15-31.

PERONI, Vera Maria Vidal; FLORES, Maria Luiza Rodrigues. Sistema Nacional, Plano nacional e gestão democrática da Educação no Brasil: articulações e tensões. In: SOUZA, Donaldo Bello de; MARTINS, Angela Maria (Orgs.). Planos de Educação no Brasil: planejamento, políticas, práticas. São Paulo: Edições Loyola, 2014. p. 147-165.

PINTO, J. M. de R. Prefácio. In: MILITÃO, A. N.; PERBONI, F. (Orgs.). Plano Nacional de Educação: diversos olhares. Curitiba: CRV, 2017, p. 17-18.

SCAFF, Elisangela Alves da Silva; OLIVEIRA Marli dos Santos de; LIMA, Simone Estigarribia de. O planejamento educacional frente às fragilidades do processo democrático brasileiro. ETD - Educação Temática Digital,20(4), 905923. 2018. 
SCAFF, Elisangela Alves da Silva; OLIVEIRA Marli dos Santos de. Planos decenais de educação: sistematização do monitoramento e avaliação nos cenários estadual e municipal. Série-Estudos,Campo Grande, MS, v. 23, n. 47, p. 141-162, jan./abr. 2018.

SCAFF, Elisangela Alves da Silva; OLIVEIRA, Marli dos Santos de; ARANDA, Flávia Paula Nogueira.Planejamento educacional e poder local na elaboração dos planos municipais de educação. Quaestio, Sorocaba, SP, v. 20, n. 1, p. 133147, abr. 2018.

SAVIANI, Dermeval. Da nova LDB ao FUNDEB.por uma outra política educacional. 2. ed. rev. e ampl. Campinas, SP: Autores Associados, 2008.

. O vigésimo ano da LDB: as 39 leis que a modificaram. Revista

Retratos da Escola, Brasília, v. 10, n. 19, p. 379-392, jul./dez. 2016.

SOUZA, Donaldo Bello de; ALCÂNTARA, Alzira Batalha. O lugar dos Conselhos Municipaisde Educação nos PMEs relativos ao PNE 2001-2010. Revista Educação em Questão, Natal, v.54, n.40, p. 191-219, jan./abr. 2016.

Recebido em 01/08/2019

Aprovado em 17/10/2019 